\title{
Fatty Acid Relationships in an Aquatic Food Chain
}

\author{
Peter F. Jezyk ${ }^{2}$ and A. John Penicnak, Zoology Department,
} University of Massachusetts, Amherst, Massachusetts

\begin{abstract}
The relationships amongst the fatty acids of the lipids from members of a model aquatic food chain were examined. The basic pattern of the fatty acids in the members, algae-brine shrimp-hydra, originated in the phytoplankton. Fatty acids in the neutral lipids of adult brine shrimp, Artemia salina, elosely resembled dietary, or algal, fatty acids, whereas the phospholipid acids differed considerably from those in the algae. Fatty acids from the total lipids of Hydra pseudoligactis fed brine shimp nauplii also resembled the dietary aeids, but more $\mathrm{C}_{20}$ polyunsaturates and fewer $\mathrm{C}_{18}$ unsaturated acids were present in those raised at $10 \mathrm{C}$ than were found at $20 \mathrm{C}$.
\end{abstract}

\section{INTRODUCTION}

L

(1) REPORTED that the fatty acids of freshwater and marine fish oils reflect the fatty acid patterns of the freshwater branchiopods (high in $C_{\perp S}$ unsaturates) and marine copepods (high in $\mathrm{C}_{20}$ and $\mathrm{C}_{22}$ polyunsaturates) on which the fish feed. In a model food chain consisting of the diatom Chaetoceros simplex, the brine shrimp Artemia salina, and the fish Lebistes reticulates, Kayama et al. (2) found that Artemia lipids contained arachidonic and eicosapentaenoic acids, Lebistes lipids had, in addition, docosatetraenoic, docosapentaenoie and docosahexaenoic acids, whereas Chaetoceros contained no highly unsaturated acids. Thus, highly unsaturated acids appeared in the food ehain beginning with less unsaturated acids. When the fish were raised at $17 \mathrm{C}$ and $24 \mathrm{C}$, the degree of unsaturation in the fatty acids was greater at the lower temperature. Farkas and Herodek (3) reported that lowering the temperature at which freshwater planktonic crustacea were grown led to an altered fatty acid pattern quite similar to that found in marine species.

Clearly, there is a continuity in the nature of fatty acids in a food chain, which is tempered by the regulatory mechanisms of members of the ehain, including their response to tem-

1 Present address: Biological Chemistry Department, University of Michigan, Ann Arbor, Michigan.

2 Present address: Pfizer Diagnastics, New York, New perature changes in the environment. These phenomena have been further explored by culturing the brine shrimp Artemia salina on algae, and feeding Hydra pseudoligactis, which were raised at $10 \mathrm{C}$ and $20 \mathrm{C}$, on Artemia nauplii. The food chain was therefore not a continuous one, the size of the brine shrimp culture required for such a chain being impractical to maintain. Each of the relationships studied must therefore be considered separately. However, the specifie relationships may be considered to be typical of those occurring in a continuous situation.

\section{EXPERIMENTAI}

Desiccated Artemia salina (Conn. Valley Biol. Supply, Southampton, Mass.) were placed in artificial sea water, the nauplii harvested 36 hr later and fed to Hydra pseudoligactis cultured according to Loomis and Lenhoff (4). Similar nauplii were grown to the adult stage at room temperature, with unicellular green algae from Long Island Sound as the food souree. Hydra were removed from continuous cultures maintained at $10 \mathrm{C}$ and $20 \mathrm{C}$ and were deprived of food for $24 \mathrm{hr}$ prior to use to insure the absence of undigested nauplii.

Lipids were extracted and washed by the method of Folch et al. (5). All washed lipid samples were evaporated to dryness under nitrogen in a tared container, weighed, and diluted to a volume suitable for preparation of the fatty acid esters by $\mathrm{BF}_{3}$-catalyzed methanolysis (6). Where noted, neutral and phospholipids were separated by silicic acid chromatography (7) before transesterification.

The methyl esters were purified on silicie acid columns and analyzed in a Glowall Corp. gas chromatograph equipped with an argon ionization detector. Six foot columns $(3.4 \mathrm{~mm}$ I.D.) packed with $15 \%$ EGS on 100/120 mesh Gas-Chrom CLZ (Applied Seience Laboratories) were used at an operating temperature of $170 \mathrm{C}$. Identifications of individual esters were made by comparison of their relative earbon numbers to those established for known acids under the same conditions (8) and the percentage composition of the samples were calculated by the method of Carroll (9). Identifications of the esters were confirmed by hydrogenation (10) and rechromatography of a portion of several ester preparations, an 
equivalence of the total amount of esters of given chain lengths found before and after hydrogenation being used as the criterion. Preparative thin-layer chromatography of the esters on silica gel plates impregnated with $25 \%$ silver nitrate (11) was also used to separate ester samples on the basis of unsaturation, each elass then being analyzed by GLC for comparison to the total esters.

\section{RESULTS}

Fatty acids from the neutral $(49.4 \mathrm{mg})$ and phospholipid $(25.3 \mathrm{mg}$ ) fractions of nauplii lipids were similar, but the phospholipids contained less palmitie and palmitoleic and more oleic and $\mathrm{C}_{20}$ polyunsaturates than the neutral lipids (Table I, cols. 1 and 2). Acids from the lipid $(6.4 \mathrm{mg}$ ) obtained from $372 \mathrm{mg}$ of algae differed considerably from those in the nauplii lipids, with less palmitoleic and oleic acids and much more linolenie acid. No acids containing more than 18 carbons were found in this lipid (Table I, col. 3). The neutral lipids $(3.6 \mathrm{mg}$ ) of adult brine shrimp ( $278 \mathrm{mg}$ ) grown on these algae had a fatty acid composition very similar to the algal lipid, with a high percentage of linolenic acid, but did contain some $\mathrm{C}_{20}$ acids, mainly eicosapentaenoic, as in the nauplii neutral lipids (Table I, col. 4). The phospholipids $(1.9 \mathrm{mg})$ of the adults were more similar to those of the nauplii phospholipids, but with reduced oleic and eicosapentaenoic and raised stearic and linoleic content.

The fatty acids from the total lipids of Hydra raised at $10 \mathrm{C}$ and $20 \mathrm{C}(3.5$ and $4.7 \mathrm{mg}$, respectively) had a pattern generally like that of the fatty acids from the brine shrimp nauplii on which they were fed (Table I, cols. 6 and 7 ). In both cases, the oleic acid level was lower, while in the $20 \mathrm{C}$ animals the linolenic acid content was higher, and in the $10 \mathrm{C}$ animals the $\mathrm{C}_{20}$ acids were increased, especially arachidonic. The total amount of unsaturation in the fat was the same in both groups, although the individual acids differed, the $10 \mathrm{C}$ group having 1.75 moles of double bonds per mole of fatty acid and the $20 \mathrm{C}$ group having 1.76 .

\section{DISCUSSION}

Fatty acids in the lipids of brine shrimp are easily altered by diet, as is evident from the considerable change in the fatty acids from egg to adult in this study and by comparison with the findings of Kayama et al. (2). The fatty acids of the diatoms in Kayama's experiments were very different from those of the algae used in our studies and the difference was reflected in the fatty acids of brine shrimp fed these algae. It is clear, however, that brine shrimp can synthesize higher polyunsaturated acids, probably through the pathways of the linolenic family (12). Phospholipid fatty acids are apparently less influenced by diet than those of the neutral lipids, as has also been suggested for crayfish lipids (13). The higher percentage of the long-chain polyunsaturates found in the phospholipid fatty acids conforms to a commonly observed pattern (14), which is thought to be related to the structural role of the phospholipids. In natural and in synthetic phospholipids, the hydrocarbon chains of those

TABLE I

Gas Chromatographic Analyses of Fatty Acid Methyl Fisters (as percent total esters)

\begin{tabular}{|c|c|c|c|c|c|c|c|}
\hline $\begin{array}{c}\text { Fatty } \\
\text { acid }\end{array}$ & $\begin{array}{l}\text { (1) } \\
\text { Brine shrimp } \\
\text { nauplii, NLa }\end{array}$ & $\begin{array}{c}\text { (2) } \\
\text { Brine shrimp } \\
\text { nauplii, PL }\end{array}$ & $\begin{array}{c}\text { (3) } \\
\text { Algae }\end{array}$ & $\begin{array}{c}\text { (4) } \\
\text { Brine shrimp } \\
\text { adults, NL }\end{array}$ & $\begin{array}{c}(5) \\
\text { Brine shrimp } \\
\text { adults, PL }\end{array}$ & $\begin{array}{l}\text { (6) } \\
\text { Hydra, } \\
10^{\circ} \mathrm{C}\end{array}$ & $\begin{array}{c}(7) \\
\text { Hydra, } \\
20^{\circ} \mathrm{C}\end{array}$ \\
\hline $14: 0$ & 1.4 & 0.3 & 0.6 & 2.8 & 1.4 & 1.0 & 0.7 \\
\hline $14: 1$ & 0.6 & 0.2 & 0.6 & 0.8 & 0.8 & 0.6 & 0.7 \\
\hline $15: 0$ & 0.4 & 0.1 & $\ldots .$. & $\mathrm{tr}$ & tr & 0.5 & 0.3 \\
\hline $15: 1$ & 0.3 & $\mathrm{tr}$ & …. & $\mathrm{tr}$ & $\mathrm{tr}$ & 0.5 & 0.7 \\
\hline $16: 0$ & 15.5 & 10.7 & 14.5 & 10.7 & 11.8 & 11,6 & 10.2 \\
\hline $16: 1$ & 16.6 & 10.9 & 5.3 & 4.0 & 12.9 & 8.4 & 8.1 \\
\hline $17: 0$ & $\operatorname{tr}$ & 0.3 & $\mathrm{tr}$ & $\mathrm{tr}$ & $\operatorname{tr}$ & 0.7 & 0.9 \\
\hline $17: 1$ & 1.4 & 1.1 & 2.4 & 2.7 & 1.6 & 1.3 & 1.7 \\
\hline $18: 0$ & 4.0 & 6.1 & 1.7 & 4.2 & 11.1 & 6.7 & 5.5 \\
\hline $18: 1$ & 30.7 & 37.8 & 20.4 & 13.9 & 24.7 & 23.4 & 24.5 \\
\hline $18: 2$ & 4.8 & 6.4 & 6.8 & 8.1 & 17.0 & 5.2 & 6.6 \\
\hline $18: 3$ & 15.8 & 13.5 & 43.0 & 45.4 & 16.6 & 16.1 & 23.7 \\
\hline $18: 4$ & 1.5 & 2.4 & ...... & 1.6 & 2.3 & 1.8 & 3.6 \\
\hline $20: 0$ & 0.2 & $\mathrm{tr}$ & … & ...... & 3.4 & 1.5 & tr \\
\hline $20: 2$ & ..... & $\mathrm{tr}$ & ….... & ….... & $\begin{array}{l}0.4 \\
\ldots \ldots\end{array}$ & $\begin{array}{l}1.2 \\
0.2\end{array}$ & \\
\hline $20: 3$ & $\mathrm{tr}$ & tr & $\ldots$ & ….... & tr & 0.3 & 0.3 \\
\hline $20: 4$ & 0.9 & 3.0 & $\ldots \ldots$ & 0.9 & 4.2 & 9.4 & 5.3 \\
\hline $20: 5$ & 5.3 & 8.0 & …... & 4.4 & 2.3 & 6.2 & 4.0 \\
\hline $22: 4$ & 1.1 & tr & ....... & ....... & tr & 1.2 & ...... \\
\hline
\end{tabular}

a $\mathrm{NL}=$ neutral lipids, $\mathrm{PL}=$ phospholipids, tr $=$ trace. 
lipids containing unsaturated fatty acids exist in an essentially liquid state at room temperature, while those with only saturated acids do not (15). This characteristic may be of considerable importance for their function in the biological system, since the liquidity determines the particular phase which ean exist at any given temperature and is in turn related to permeability processes.

Hydra fed on brine shrimp nauplii display a fatty acid pattern similar to that of the nauplii but cold-adapted Hydra have a higher concentration of the $\mathrm{C}_{20}$ and $\mathrm{C}_{22}$ unsaturated fatty acids and smaller amounts of the lesshighly unsaturated $\mathrm{C}_{18}$ acids than do the $20 \mathrm{C}$ animals. A similar inerease in docosahexaenoie and other unsaturated acids has been noted in the brain lipids of goldfish exposed to lowered temperatures while maintained on a constant diet (16). Such regulations of unsaturation in homeotherms also has long been known (17). Johnston and Roots (16) suggest that the process of temperature acclimation involves the ability to control the degree of unsaturation of cellular lipids, thereby maintaining the specifie liquid-erystalline state of the cell membranes. From our results, it would appear that the specific type of acids in the lipids, not just the total amount of unsaturates, may be important in this control.

The results of this study support the view that the higher members of aquatic food chains maintain a degree of control over the composition of their fatty acids, and particularly of the polyunsaturates, but that the basic pattern originates in the primary members of the chain, the phytoplankton, and is carried throughout the chain. Fatty acids of phytoplankton are known to be considerably altered by such factors as the availability of nitrate, the age of the culture and the temperature $(3,18)$, thus allowing a great variability in the acids of any given food chain. The need for control of phospholipid liquidity could therefore be the basic cause of the higher percentage of polyunsaturated fatty acids in the lipids of animals from the colder marine waters. Nentral lipids may not be primarily affected in this way, as suggested by the present investigation and also by Van Handel (19), who has reported that the synthesis of fatty acids into the triglycerides of mosquitos is unaffected by temperature. Such variation might occur secondarily, however, as a result of the turnover of fatty acids from endogenous phospholipids.

\section{ACKNOWLEDGMENTS}

Supported in part by grants No. AI-04953 and GM 06877 , US Public Health Service.

\section{REFERENCES}

1. Lovern, J. A., Biochem. J. 29, 847-849 (1935).

2. Kayama, M., Y. Tsuchiya and J. F. Mead, Bull. Jap. Soc. Sci. Fish. 29, 452-458 (1963).

3. Farkas, T., and S. J. Herodek, J. Lipid Res, 5, 369-373 (1964).

4. Loomis, W. F., and M. Lenhoff, J. Exp. Zool. 132, 555-568, (1956).

5. Folch, J., M. Lees and G. H. Sloane Stanley, J. Biol. Chem. $226,497-509$ (1957).

6. Borgstrom, B., Acta Physiol. Scand. 25, 101-110 (1952).

7. Morrison, W. R., and L. M. Smith, J. Lipid Res. $5,600-608$ (1964).

8. Rahm, J. J, and R. T. Holman, J. Nutr. 84, 15-19 (1964).

9. Farquhar, J. W., W. Insull, P. Rosen, W. Stoffel and Ahrens, E. H., Nutr. Rev, 17, 1-30 (1959).

10. Carroll, K. K., Nature 191, 377-378 (1961).

11. deVries, B., JAOCS 41, 403-406 (1964).

12. Klenk, E., Experentia.17, 199-204 (1961); Mead, J. F., Fed. Proc. 20, 952-955 (1961).

13. Wolfe, D. A. P. V. Rao and D. G. Cornwell, JAOCS $42,633-637$ (1965).

14. Carroll, K. K., Ibid. 42, 516-528 (1965).

15. Chapman, D., Ibid. 42, 353-371 (1965).

16. Johnston, P. V., and B. J. Roots, Comp. Biochem. Physiol. 11, 303-309 (1964).

17. Henriques, V., and C. Hansen, Scand, Arch. Physiol, 11, 151 (1901).

18. Ackman, R. G., P. M. Jangaard, R. J. Hoyle and H. Brockerhoff, J. Fish. Res. Bd. Canada 21, 747-756 (1964).

19. Van Handel, E. J., J, Jipid Res. 7, 112-115 (1966).

[Received January 28, 1966] 